Canadian Journal of Soil Science Revue canadienne de la science du sol

\title{
CALIBRATION OF WHATMAN GRADE 42 FILTER PAPER FOR SOIL SUCTION MEASUREMENT
}

\begin{tabular}{|r|l|}
\hline Journal: & Canadian Journal of Soil Science \\
\hline Manuscript ID & CJSS-2016-0064.R2 \\
\hline Manuscript Type: & Review \\
\hline Complete List of Authors: & $\begin{array}{l}\text { Kim, Hobi; Fugro Consultants, Inc, } \\
\text { Prezzi, Monica; Purdue University, Lyles School of Civil Engineering } \\
\text { Salgado, Rodrigo; Purdue University, Lyles School of Civil Engineering }\end{array}$ \\
\hline Keywords: & $\begin{array}{l}\text { Unsaturated soil, suction measurement, filter paper technique, Whatman } \\
\text { Grade 42 filter paper, calibration. }\end{array}$ \\
\hline \multicolumn{2}{|c}{} \\
\hline
\end{tabular}




\section{CALIBRATION OF WHATMAN GRADE 42 FILTER PAPER FOR SOIL SUCTION MEASUREMENT}

* Hobi Kim, Project Manager, Fugro Consultants, Inc., 6100 Hillcroft Ave, Houston, Texas 77081, U.S.A.

Monica Prezzi, Professor, Lyles School of Civil Engineering, Purdue University, West Lafayette, IN 47907-1284, U.S.A.

Rodrigo Salgado, Charles Pankow Professor in Civil Engineering, Lyles School of Civil Engineering, Purdue University, West Lafayette, IN 47907-1284, U.S.A.

Corresponding Author: Project Manager, Fugro Consultants, Inc., 6100 Hillcroft Ave, Houston, Texas 77081, U.S.A..

Tel: (765) 337-3636, e-mail: hobicom@gmail.com 


\title{
CALIBRATION OF WHATMAN GRADE 42 FILTER PAPER FOR SOIL SUCTION MEASUREMENT
}

\begin{abstract}
The filter paper technique consists of obtaining the equilibrium water content of a filter paper that is either in direct contact with a soil sample or inside an airtight container together with the sample but not in direct contact with it. After the final water content of the filter paper is determined, the suction in the soil is estimated from a previously established calibration curve relating the filter paper water content and suction. The ASTM D5298-10 calibration curve is routinely used for indirect suction estimation from Whatman Grade 42 filter paper water content measurements. This note identifies limitations in the calibration curve in ASTM D5298-10 that lead to inaccuracies in the estimation of suction values, particularly for very low filter paper water contents. The paper proposes new equations not subject to these limitations for the calibration curve for Whatman Grade 42 filter paper using the same data used to construct the calibration curve in ASTM D5298-10.
\end{abstract}

Keywords: Unsaturated soil, suction measurement, filter paper technique, Whatman Grade 42 filter paper, calibration. 


\section{INTRODUCTION}

Soil suction has proven to be a challenging variable to measure (Delage et al. 2008; Fredlund et al. 2012). Out of the several indirect methods available for suction measurement, the filter paper technique is the most often used to estimate soil suction since it is simple and reliable (Fawcett and Collis-George 1967; Al-Khafaf and Hanks 1974; Hamblin 1981; Daniel et al. 1981; Ching and Fredlund 1984; Chandler and Gutierrez 1986). The principle of measurement of suction using the filter paper technique is that the pore water within a soil sample flows to an initially dry filter paper until (i.e., the filter paper and the soil) hydraulic equilibrium is reached. By measuring the equilibrated water content of the filter paper, the soil suction is indirectly estimated using a previously established calibration curve relating suction values to the filter paper water content. Equilibration of suction between the soil sample and the filter paper may be achieved through the vapor gap between the sample and the paper (if both are enclosed in an airtight container) or through direct contact between the soil sample and the filter paper. The filter paper water content is related to total suction if equilibration is achieved through the vapor gap and to matric suction if equilibration is achieved through direct contact between the soil sample and the filter paper. Although the filter paper is allowed to be in direct contact with the soil surface, there is a transition corresponding to the equilibration of the water content of the filter paper with that of the soil from liquid flow being dominant to vapor flow being dominant with increasing soil suction (Fredlund et al. 1995).

The matric suction measured using the filter paper technique is affected by several factors, such as hysteresis on wetting and drying, equilibration time, and the quality and type of the filter paper (Kim et al. 2015). Since filter paper is a porous material, it experiences hysteresis upon wetting and drying, which may result in differences in measured suction for the same filter paper 
water content. In addition, equilibrium between the filter paper and the soil sample must be ensured to have the filter paper water content reflect the suction in the soil. The time required for equilibrium depends on the type of soil, soil suction and the test method (i.e., indirect or direct contact with soil) and should be determined based on several trial tests.

Based on a review of test data available in the literature, Leong et al. (2002) showed that the performance of Whatman Grade 42 filter paper (hereafter referred to as Whatman No. 42 filter paper) was more consistent than that of Schleicher \& Schuell No. 589 filter paper. Several studies in the literature established and evaluated calibration curves for soil suction estimation using Whatman No. 42 filter paper (Fawcett and Collis-George 1967; Hamblin 1981; Chandler and Gutierrez 1986; Greacen et al. 1987; Chandler et al. 1992; Houston et al. 1994; Deka, R.N., Wairiu, M., Mtakwa, P.W., Mullins, C.E.., Veenendaal, E.M., Townend 1995; Leong et al. 2002; Power et al. 2008). Although some studies proposed the use of separate calibration curves for matric suction and total suction estimation (e.g., Houston et al. 1994; Leong et al. 2002; Power et al. 2008), Marinho and Oliveira (2006) indicated that there is a unique relationship between the filter paper water content and suction. Leong et al. (2002) pointed out that the differences between the calibration curves in the literature could be attributed to the initial water content of the filter paper (i.e., whether testing was performed using an initially dry or wet filter paper).

The calibration curves presented in ASTM D5298-10 and in Chandler et al. (1992) for Whatman No. 42 filter paper are often used in research to obtain soil suction values. This technical note revisits the development of the calibration curves presented in ASTM D5298-10. After carefully reviewing the calibration procedure followed in the development of the calibration curve in ASTM D5298-10, a few limitations of the calibration procedures were identified that affect the accuracy of the calibration curve. Using the same data on which 
construction of the calibration curve in ASTM D5298-10 is based, a regression analysis is performed and new equations are proposed for the calibration curve using Whatman No. 42 filter paper.

\section{WHATMAN NO 42 FILTER PAPER CALIBRATION CURVE}

Most calibration curves that have been proposed for the Whatman No. 42 filter paper are bilinear in logarithm of suction vs. filter paper water content space (Fawcett and Collis-George 1967; Chandler and Gutierrez 1986; Greacen et al. 1987; Chandler et al. 1992; Houston et al. 1994; Deka et al. 1995; Leong et al. 2002; Power et al. 2008). The break in the line (slope discontinuity) takes place for filter paper water contents ranging from 38 to $47 \%$. Each of the two segments can be expressed as:

$$
\log S=\mathrm{a}\left(w c_{f p}\right)+b
$$

where $S$ denotes suction in $\mathrm{kPa}, a$ is the slope of the line, $w c_{f p}$ is the gravimetric filter paper water content in percentage, and $b$ is the y intercept. As an example, Figure 1 shows the ASTM D529810 calibration curve.

The bilinear shape of the calibration curve for the filter paper may be understood by considering the water absorption characteristics of the filter paper (Greacen et al. 1987). As shown in Figure 2, the filter paper is composed of a porous matrix of cellulose fibers. The amount of water absorbed by a filter paper is governed by either its pores at high filter paper water contents or by its cellulose fibers at low filter paper water contents.

Figure 3 shows Environmental Scanning Electron Microscope (ESEM) images of dry and wet cellulose fibers of Whatman Grade 5 paper. Figure 3 shows that the cellulose fibers of the 
Whatman paper swell and increase in diameter with wetting, while the connection points between the cellulose fibers remain fixed (Mah 2012).

Table 1 summarizes the equations for the Whatman No. 42 filter paper calibration curves available in the literature. The equations in Table 1 have been proposed based on filter paper water content and suction measurements made using different tests (Fawcett and Collis-George 1967; Hamblin 1981; Greacen et al. 1987; Deka, R.N., Wairiu, M., Mtakwa, P.W., Mullins, C.E.., Veenendaal, E.M., Townend 1995).

Figure 4 shows the calibration curves for all the equations summarized in Table 1. Out of all calibration curves shown in Figure 4, ASTM D5298-10 adopted the equations proposed by Greacen et al. (1987) which were developed using the data originally presented in Fawcett and Collis-George (1967). Table 2 reproduces the data (denoted as Data set 1 in Table 1 and Figure 4) provided in Greacen et al. (1987). Note that the equation proposed by Greacen et al. (1987) for $\mathrm{w}_{\mathrm{fp}}>0.453$ based on their own test results (denoted as Data set 2 in Table 1) was not adopted by ASTM D5298-10.

The calibration equations in ASTM D5298-10 (see Figure 1) can be obtained by:

(1) Determining the fitting parameters appearing in Equation 1 based on Data set 1 [mean values of Fawcett and Collis-George (1967) data, as provided by Greacen et al. (1987)] and rounding them off to the nearest hundredth (i.e., -17.93 and -3.10; see Table 1);

(2) Dividing the terms on both sides of the equations by 2.3026 , where 2.3026 is the natural logarithm of $10[\ln (10)]$ rounded off to the nearest ten-thousandth.

Following these steps, the natural logarithm of suction appearing in the equations can be replaced by the common logarithm of suction, as is the case in ASTM D5298-10 (see Figure 1). 
However, rounding off the slope parameters of the calibration curve equations may lead to erroneous suction values, especially when suction values are large. Also, Greacen et al. (1987) developed the calibration curve equations by performing a regression analysis on the rounded off mean values of the filter paper water contents provided in Fawcett and Collis-George (1967). Table 3 shows the test results originally presented by Fawcett and Collis-George (1967). The suction values and the mean values of the filter paper water contents are slightly different in Table 2 and Table 3. These errors can be avoided by using the original data by Fawcett and Collis-George (1967) (see Table 3). Figure 5 shows the calibration curve obtained by performing a regression analysis on the suction values and the mean values of the filter paper water contents provided in Table 3Error! Reference source not found..

The equations for the ASTM D5298-10 calibration curve shown in Figure 1 are similar to the ones in Figure 5, however, for small filter paper water contents, the suction values obtained from Figure 1 and Figure 5 are different. For example, at a filter paper water content of 27.5\%, suction values of $1,530 \mathrm{kPa}$ and $1,556 \mathrm{kPa}$ are obtained from the ASTM D5298-10 calibration curve and Figure 5, respectively. The difference in suction values becomes larger as the filter paper water content decreases. Moreover, since all the filter paper water contents associated with the mean values shown in Figure 5 were available in Fawcett and Collis-George (1967), as given in Table 3, a regression analysis was also performed using all the Fawcett and Collis-George (1967) data together with the Greacen et al. (1987) data. Figure 6 shows the proposed suctionwater content calibration curve valid for tests performed with initially dry Whatman No. 42 filter paper. Table 4 gives the suction values for filter paper water contents ranging from $6.5 \%$ to $150 \%$ calculated using the ASTM D5298-10 equations and the calibration equations from Figure 5 and Figure 6. 
As shown in Figure 6, the following equations result for the proposed calibration curve:

$$
\log _{10}(S)=5.336-0.0779\left(w c_{f p}\right)
$$

for $\mathrm{wc}_{\mathrm{fp}}>45.47 \%$ and

$$
\log _{10}(S)=2.394-0.0132\left(w c_{f p}\right)
$$

for $\mathrm{wc}_{\mathrm{fp}}<45.47 \%$ :

where $\mathrm{wc}_{\mathrm{fp}}$ is the filter paper water content $(\%)$, and $\mathrm{S}$ is the suction in $\mathrm{kPa}$.

Considering the test conditions in the work reported by Fawcett and Collis-George (1967), the proposed equations can only be used when the wetting testing procedure is followed (starting out with dry filter papers). Also, the calibration curves should be used only for filter paper water content greater than $6.5 \%$.

\section{SUMMARY AND CONCLUSIONS}

The available calibration curve equations for suction estimation using the filter paper technique with Whatman No. 42 filter paper were reviewed in this paper. All calibration curves are applicable to a wide range of filter paper water contents and have a bilinear shape on logarithm of suction vs. filter paper water content space.

In order to improve suction predictions, a calibration curve was proposed in this paper based on a regression analysis performed on the original data set used to construct the ASTM D5298-10 calibration curve. The difference in suction estimates from the ASTM D5298-10 calibration curve and the proposed calibration curve can be significant in rigorous work, as high 
as $1,386 \mathrm{kPa}$ at a filter paper water content of $6.5 \%$. As the filter paper water content increases, this difference becomes increasingly smaller and can be considered to be unimportant. 


\section{REFERENCES}

ASTM D5298-10, 2010: Standard Test Method for Measurement of Soil Potential (Suction) Using Filter Paper, Annual Book of ASTM Standards, ASTM International, West Conshohocken, PA.

Al-Khafaf, S., and Hanks, R., 1974, "Evaluation of the filter paper method for estimating soil water potential," Soil Sci., Vol. 117, No. 4, pp. 194-204.

Chandler, R. J., Crilly, M. S., and Montgomery-Smith, G., 1992, "A low-cost method of assessing clay desiccation for low-rise buildings.," Proc. Inst. Civ. Eng., Vol. 92, No. 2, pp. 82-89.

Chandler, R. J., and Gutierrez, C. I., 1986, "The filter-paper method of suction measurement," Géotechnique, Vol. 36, No. 2, pp. 265-268.

Ching, R., and Fredlund, D., 1984, “A small Saskatchewan town copes with swelling clay problems," Proc. 5th Int. Conf. Expans. Soils, pp. 1-7.

Daniel, D., Hamilton, J., and Olson, R., 1981, "Suitability of thermocouple psychrometers for studying moisture movement in unsaturated soils,", in Zimmie, T.F., Riggs, C.O. ed., Permeability and groundwater contaminant transport : symposium / ASTM Committee D-18 on Soil \& Rock for Engineering Purposes: American Society for Testing \& Materials, , 1723 June 1979, Philadelphia, pp. 84-100.

Deka, R.N., Wairiu, M., Mtakwa, P.W., Mullins, C.E.., Veenendaal, E.M., and Townend, J., 1995, "Use and accuracy of the filter-paper technique for measurement of soil matric potential,” Eur. J. Soil Sci., Vol. 46, No. June, pp. 233-238.

Delage, P., Romero, E., and Tarantino, A., 2008, "Recent developments in the techniques of controlling and measuring suction in unsaturated soils,", in 1st European Conference on Unsaturated Soils, CRC Press, Durham, pp. 33-52.

Fawcett, R. G., and Collis-George, N., 1967, "A filter-paper method for determining the moisture characteristics of soil," Aust. J. Exp. Agric. Anim. Husb., Vol. 7, pp. 162-167.

Fredlund, D., Gan, J., and Gallen, P., 1995, "Suction measurements on compacted till specimens and indirect filter paper calibration technique," Transp. Res. Rec., Vol. 1481, pp. 3-9.

Fredlund, D. G., Rahardjo, H., and Fredlund, M. D., 2012, “Unsaturated Soil Mechanics in Engineering Practice," John Wiley \& Sons, Inc., Hoboken, NJ, USA.

Greacen, E. L., Walker, G. R., and Cook, P. G., 1987, "Evaluation of the filter paper method for measuring soil water suction,", in International Conference on Measurement of Soil and Plant Water Status, pp. 137-143. 
Hamblin, A., 1981, "Filter-paper method for routine measurement of field water potential," $J$. Hydrol., Vol. 53, pp. 355-360.

Houston, S., Houston, W., and Wagner, A., 1994, "Laboratory filter paper suction measurements," ASTM Geotech. Test. J., Vol. 17, No. 2, pp. 185-194.

Kim, H., E. Ganju, D. Tang, M. Prezzi, and Salgado, R. (2015). "Matric Suction Measurements of Compacted Fine-grained Soils using the Filter Paper Technique" Road Materials and Pavement Design, Vol. 16, No. 2, pp. 358-378.

Leong, E., He, L., and Rahardjo, H., 2002, "Factors affecting the filter paper method for total and matric suction measurements," ASTM Geotech. Test. J., Vol. 25, No. 3, pp. 1-12.

Mah, E.G. (2012). Fabrication of paper based thermo-responsive membranes and investigation for their use in adsorption of emerging water contaminants. Masters thesis submitted to the faculty of McMaster University, Hamilton, Ontario.

Marinho, F., and Oliveira, O., 2006, “The filter paper method revisited," ASTM Geotech. Test. J., Vol. 29, No. 3, pp. 1-9.

Power, K., Vanapalli, S., and Garga, V., 2008, “A revised contact filter paper method,” ASTM Geotech. Test. J., Vol. 31, No. 6, pp. 1-9. 


\section{List of figures}

Figure 1 - Calibration curve for Whatman No. 42 paper based on the wetting testing procedure (modified after ASTM D5298-10).

Figure 2 - Scanning Electron Microscope (SEM) image of Whatman No. 42 filter paper.

Figure 3 - Environmental Scanning Electron Microscope (ESEM) images of Whatman Grade 5 paper (a) dry, and (b) wet (modified after Mah 2012).

Figure 4 - Comparison of calibration curves for Whatman No. 42 filter paper.

Figure 5 - Revised calibration suction-filter paper water content curve for wetting of Whatman No. 42 paper.

Figure 6 - Proposed calibration suction-filter paper water content curve for wetting of Whatman No. 42 paper. 


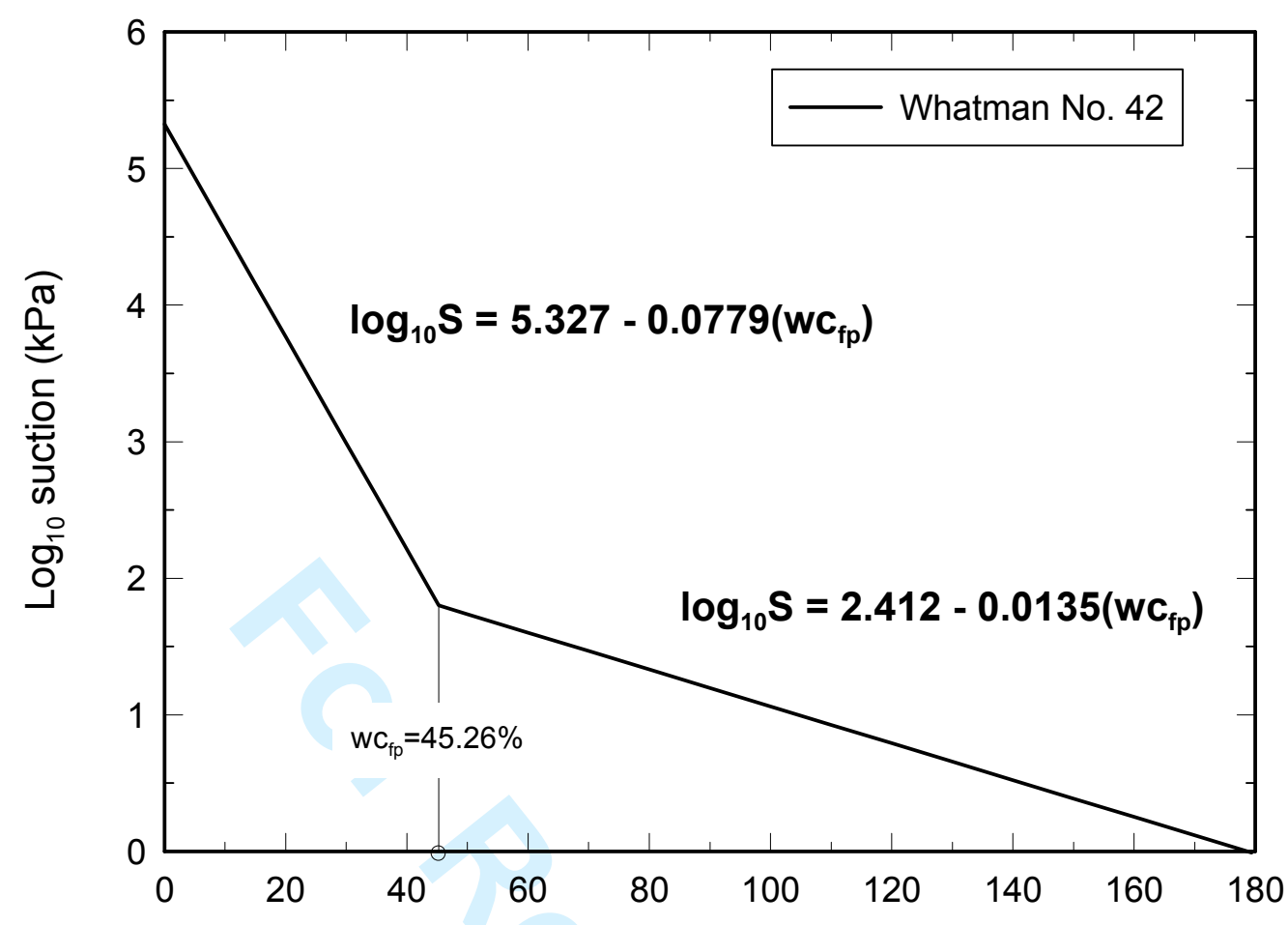

Filter paper water content $\mathrm{wc}_{\mathrm{fp}}(\%)$

Figure 1 - Calibration curve for Whatman No. 42 paper based on the wetting testing procedure (modified after ASTM D5298-10). 


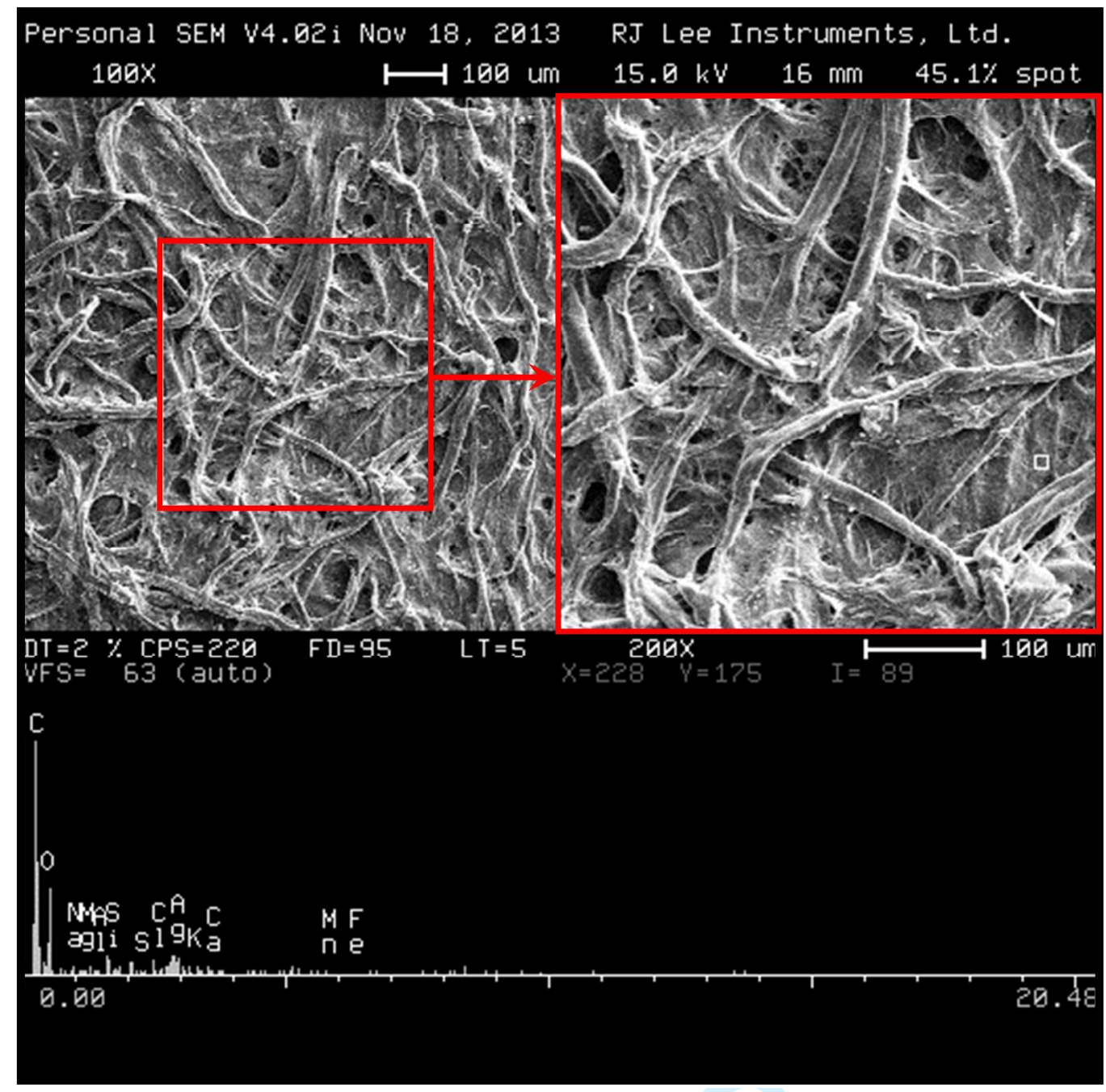

Figure 2 - Scanning Electron Microscope (SEM) image of Whatman No. 42 filter paper. 


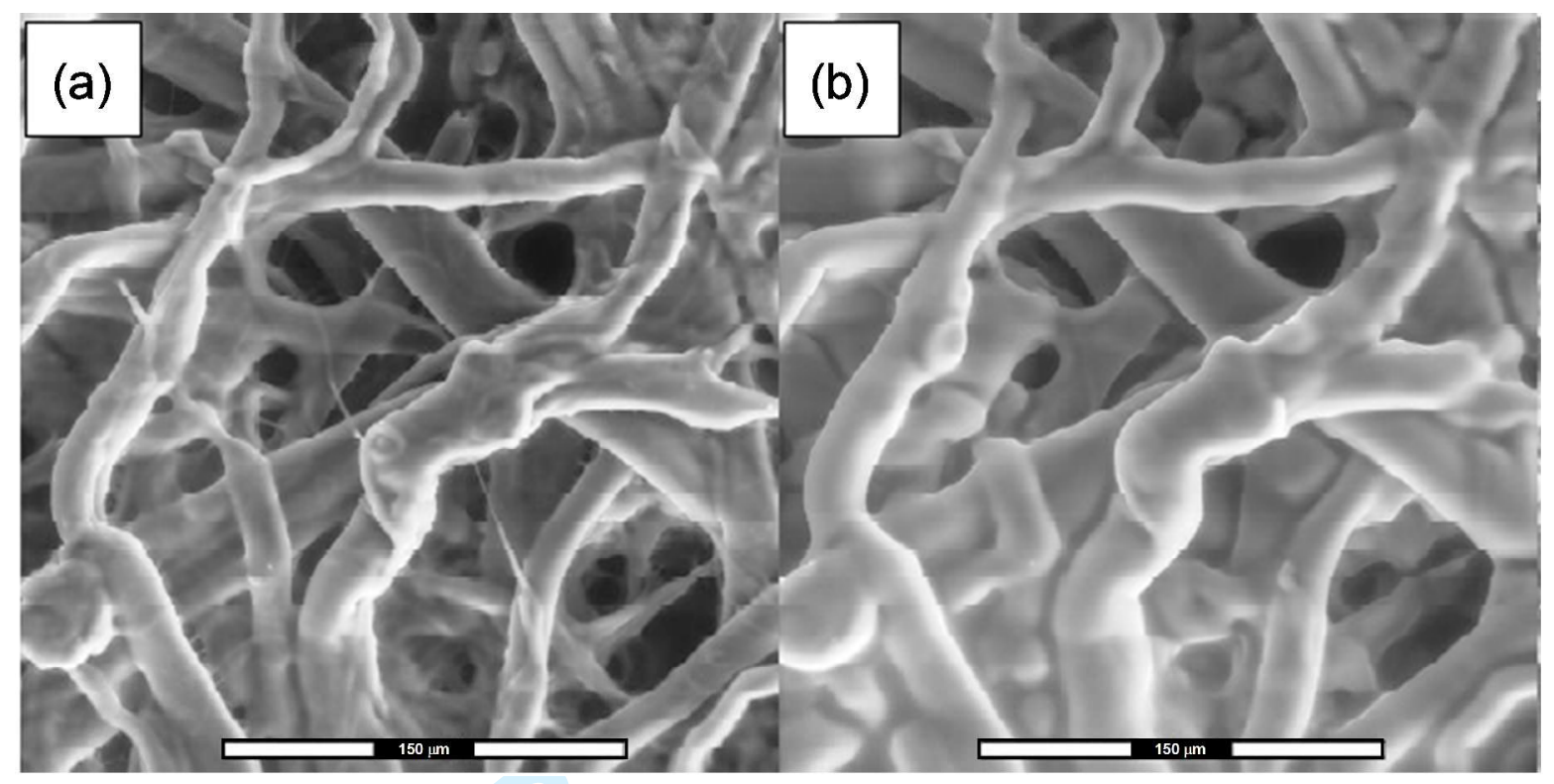

Figure 3 - Environmental Scanning Electron Microscope (ESEM) images of Whatman Grade 5 paper (a) dry, and (b) wet (modified after Mah 2012). 


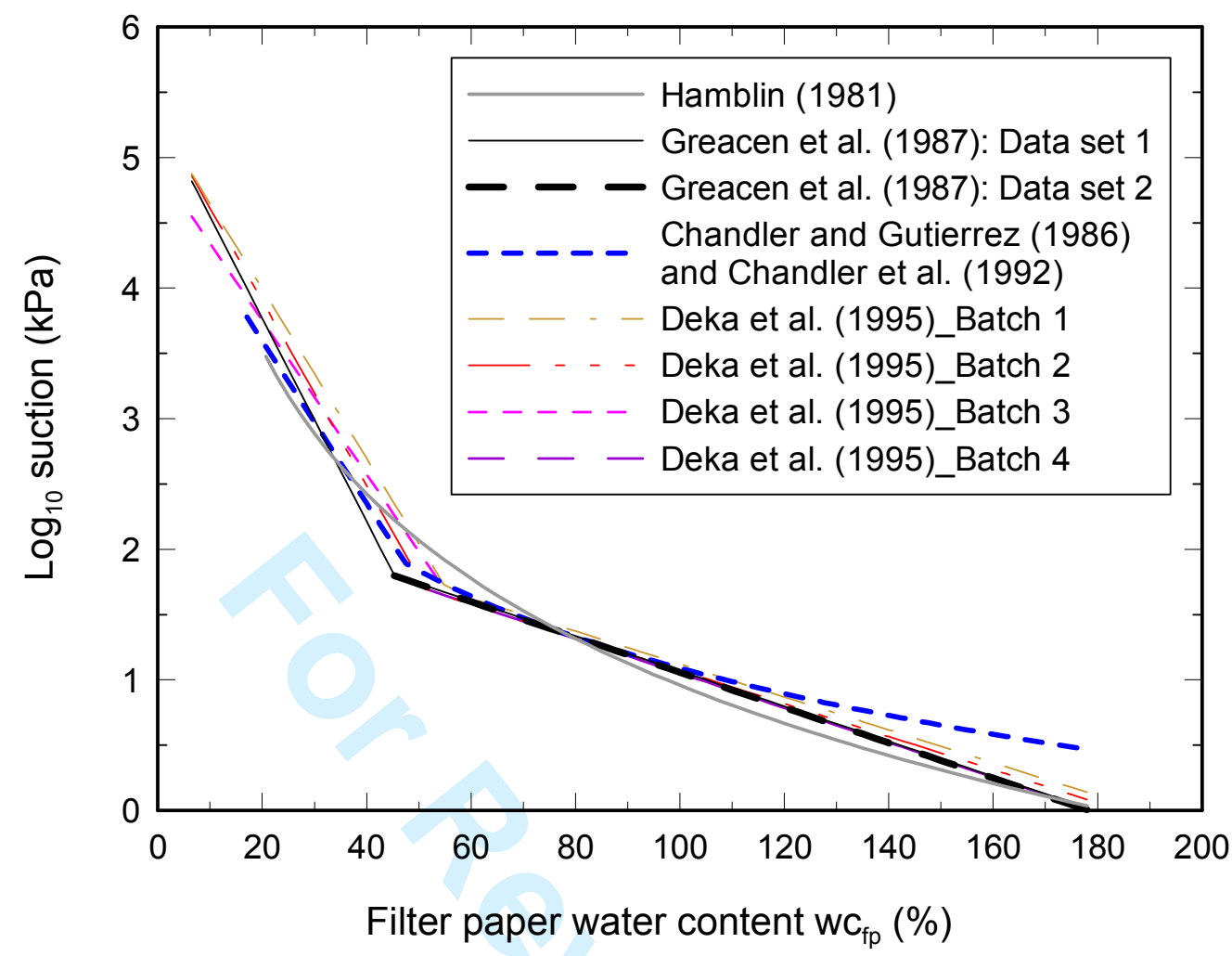

Figure 4 - Comparison of calibration curves for Whatman No. 42 filter paper. 


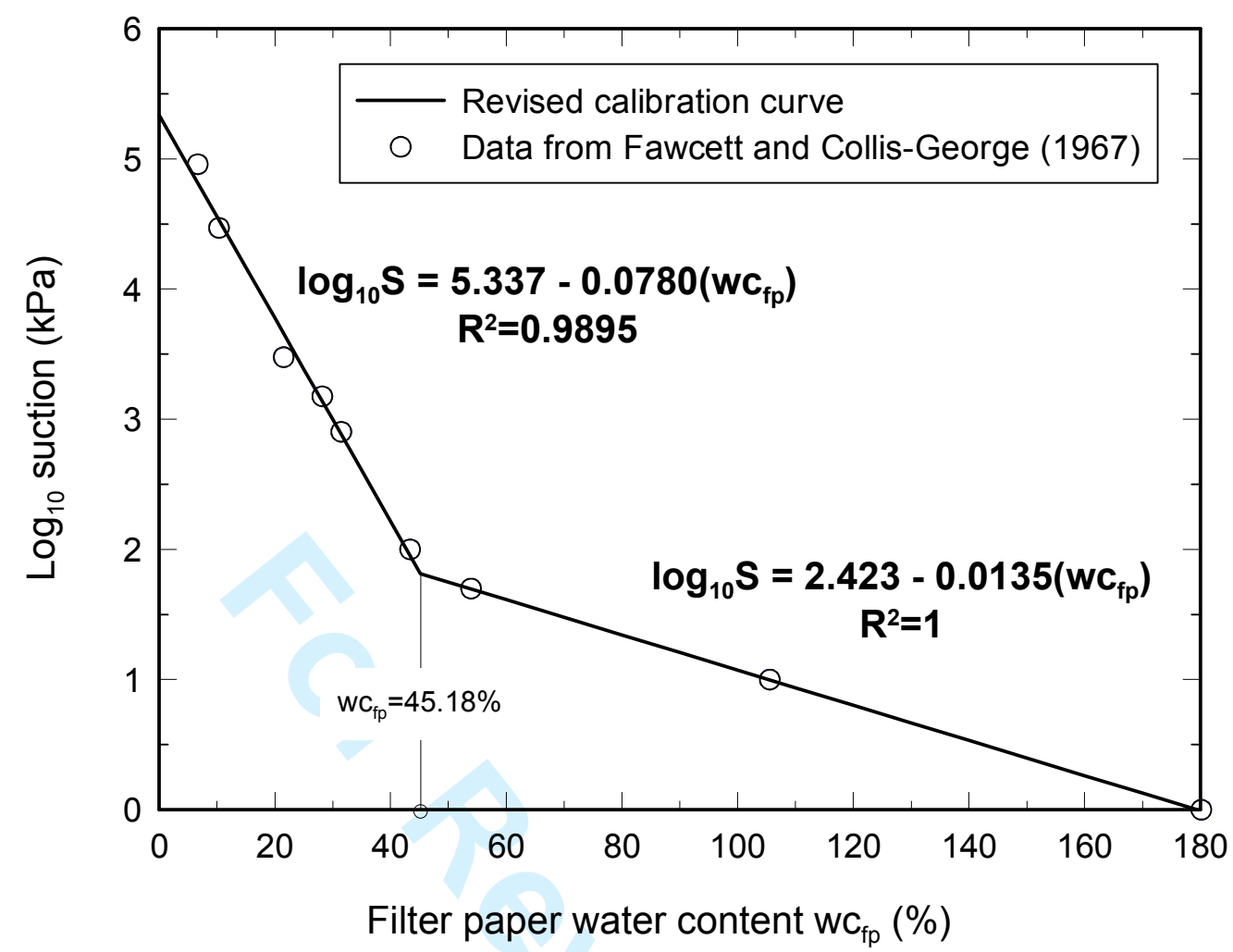

Figure 5 - Revised calibration suction-filter paper water content curve for wetting of Whatman No. 42 paper. 


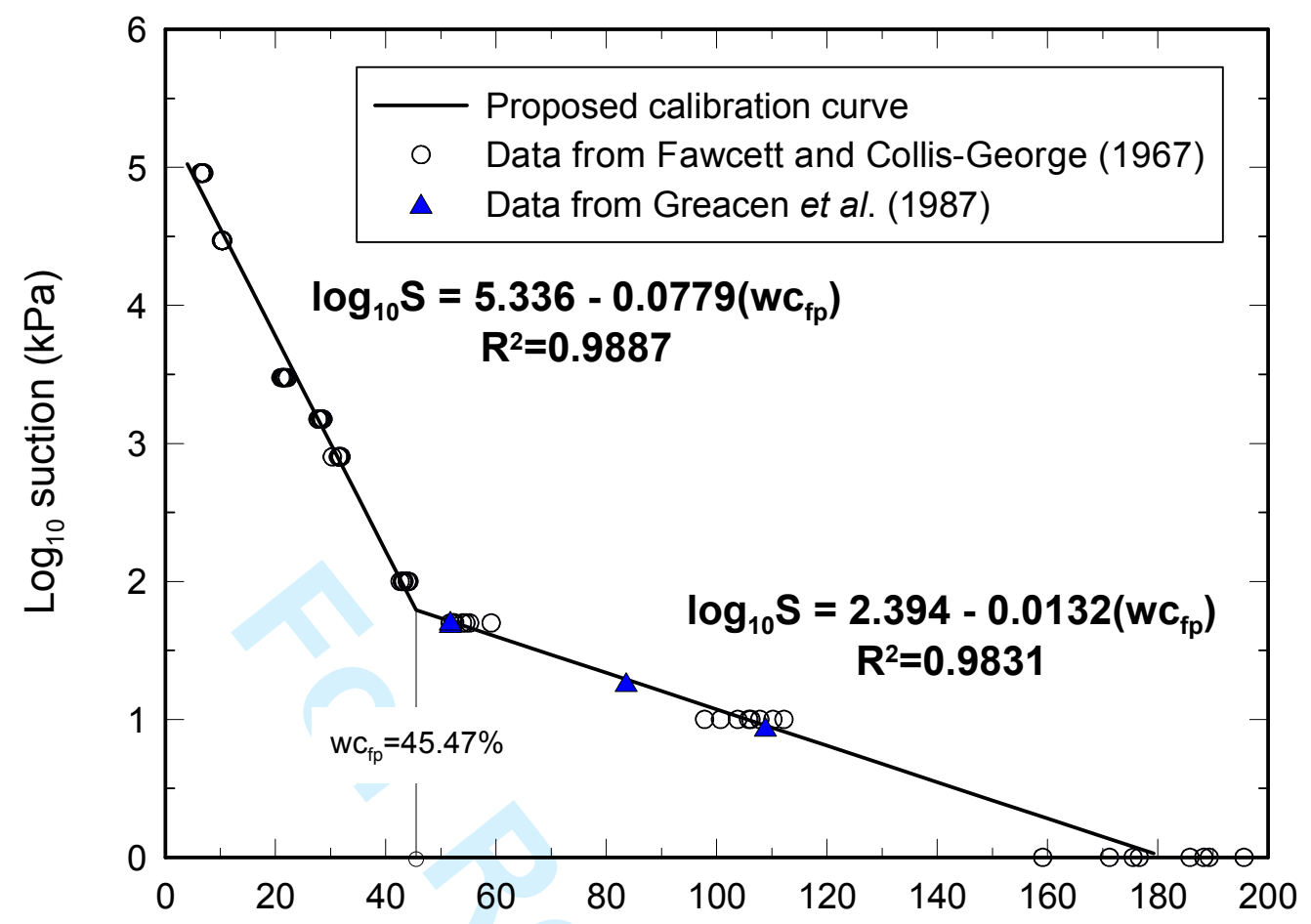

Filter paper water content $w_{c_{f p}}(\%)$

Figure 6 - Proposed calibration suction-filter paper water content curve for wetting of Whatman No. 42 paper. 


\section{List of tables}

Table 1. Calibration curves for Whatman No. 42 filter paper.

Table 2. Data used in the development of the equations proposed in ASTM D5298-10 [Fawcett and Collis-George (1967), as cited by Greacen et al. (1987)].

Table 3. Test data originally presented in Fawcett and Collis-George (1967).

Table 4. Comparisons of suction values calculated using different calibration equations. 
Table 1. Calibration curves for Whatman No. 42 filter paper.
Reference
Calibration equations available in the literature $^{a}$
Notes

\begin{tabular}{|c|c|c|}
\hline $\begin{array}{l}\text { Fawcett and } \\
\text { Collis-George } \\
\quad(1967)\end{array}$ & $\begin{array}{l}\text { No equation: calibration curve was } \\
\text { presented in a graph based on curve } \\
\text { fitting by eye. }\end{array}$ & $\begin{array}{l}\text { See original data in Error! } \\
\text { Reference source not found.. }\end{array}$ \\
\hline Hamblin (1981) & $\begin{array}{l}\log _{10} \mathrm{~S}=8.325-3.683 \log _{10}\left(\mathrm{wc}_{\mathrm{fp}}\right) \\
\text { [applicable to matric suction values less } \\
\text { than } 3 \mathrm{MPa} \text {, associated with } \\
\left(\mathrm{wc}_{\mathrm{fp}}\right)>20.72 \% \text { ] }\end{array}$ & $\begin{array}{l}\text { Original equation was proposed } \\
\text { based on the natural logarithm of } \\
\text { suction and filter paper water } \\
\text { content values. }\end{array}$ \\
\hline $\begin{array}{c}\text { Chandler and } \\
\text { Gutierrez (1986) }\end{array}$ & $\begin{array}{l}(\text { Suction in } \mathrm{pF})=5.850-0.0622\left(\mathrm{wc}_{\mathrm{fp}}\right) \\
\text { the equation is restricted to suction } \\
\text { values ranging from } 80 \text { to } 6,000 \mathrm{kPa} \text { ] }\end{array}$ & $\begin{array}{l}\text { Equation based on Chandler and } \\
\text { Gutierrez (1986) data together } \\
\text { with data by Fawcett and Collis- } \\
\text { George (1967) and Hamblin } \\
\text { (1981). }\end{array}$ \\
\hline \multirow[t]{2}{*}{$\begin{array}{l}\text { Greacen et al. } \\
\quad(1987)\end{array}$} & $\begin{aligned}\left(\mathrm{w}_{\mathrm{fp}}\right)<0.453: \\
\quad \ln \mathrm{S}=12.265-17.931\left(\mathrm{w}_{\mathrm{fp}}\right) \\
\left(\mathrm{w}_{\mathrm{fp}}\right)>0.453: \\
\quad \ln \mathrm{S}=5.553-3.095\left(\mathrm{w}_{\mathrm{fp}}\right)\end{aligned}$ & $\begin{array}{l}\text { Data set 1: Based only on mean } \\
\text { values of the data of Fawcett and } \\
\text { Collis-George (1967) (see data in } \\
\text { Error! Reference source not } \\
\text { found.). }\end{array}$ \\
\hline & $\left(\mathrm{w}_{\mathrm{fp}}\right)>0.453: \ln \mathrm{S}=5.547-3.11\left(\mathrm{w}_{\mathrm{fp}}\right)$ & $\begin{array}{l}\text { Data set 2: Based on the test } \\
\text { results by Greacen et al. (1987). }\end{array}$ \\
\hline $\begin{array}{l}\text { Chandler et al. } \\
\text { (1992) }\end{array}$ & $\begin{aligned} &\left(\mathrm{wc}_{\mathrm{fp}}\right)<47 \%^{b}: \\
& \log _{10} \mathrm{~S}=4.84-0.0622\left(\mathrm{wc}_{\mathrm{fp}}\right) \\
&\left(\mathrm{wc}_{\mathrm{fp}}\right)>47 \%> \\
& \log _{10} \mathrm{~S}=6.05-2.48 \log _{10}\left(\mathrm{wc}_{\mathrm{fp}}\right)\end{aligned}$ & $\begin{array}{l}\text { For }\left(\mathrm{wc}_{\mathrm{fp}}\right)<47 \% \text {, the calibration } \\
\text { equation is exactly the same as } \\
\text { that of Chandler and Gutierrez } \\
(1986) \text {. }\end{array}$ \\
\hline \multirow{4}{*}{ Deka et al. (1995) } & $\begin{array}{l}(\mathrm{S})>47.9 \mathrm{kPa}: \log _{10} \mathrm{~S}=5.297-6.507\left(\mathrm{w}_{\mathrm{fp}}\right) \\
(\mathrm{S})<47.9 \mathrm{kPa}: \log _{10} \mathrm{~S}=2.380-1.259\left(\mathrm{w}_{\mathrm{fp}}\right)\end{array}$ & Batch 1 \\
\hline & $\begin{array}{l}(\mathrm{S})>47.9 \mathrm{kPa}: \log _{10} \mathrm{~S}=5.320-7.083\left(\mathrm{w}_{\mathrm{fp}}\right) \\
(\mathrm{S})<47.9 \mathrm{kPa}: \log _{10} \mathrm{~S}=2.338-1.266\left(\mathrm{w}_{\mathrm{fp}}\right)\end{array}$ & Batch 2 \\
\hline & $(\mathrm{S})>50 \mathrm{kPa}: \log _{10} \mathrm{~S}=4.932-5.896\left(\mathrm{w}_{\mathrm{fp}}\right)$ & Batch $3^{c}$ \\
\hline & $(\mathrm{S})<50 \mathrm{kPa}: \log _{10} \mathrm{~S}=2.377-1.326\left(\mathrm{w}_{\mathrm{fp}}\right)$ & Batch $4^{c}$ \\
\hline ASTM D 5298-10 & $\begin{array}{l}\left(w_{\mathrm{fp}}\right)<45.3 \%: \\
\log _{10} \mathrm{~S}=5.327-0.0779\left(\mathrm{wc}_{\mathrm{fp}}\right) \\
\left(\mathrm{wc}_{\mathrm{fp}}\right)>45.3 \%: \\
\log _{10} \mathrm{~S}=2.412-0.0135\left(\mathrm{wc}_{\mathrm{fp}}\right)\end{array}$ & $\begin{array}{l}\text { Based on Data set } 1 \text { in Greacen } \\
\text { et al. (1987). }\end{array}$ \\
\hline
\end{tabular}

Note: The equations for the Whatman No. 42 filter paper calibration curves in the literature ${ }^{a}\left(\mathrm{wc}_{\mathrm{fp}}\right)$ : gravimetric water content of the filter paper in percentage; $\left(\mathrm{w}_{\mathrm{fp}}\right)$ : gravimetric water content of the filter paper in decimal fraction.

${ }^{b}$ The equation is limited to suction values of up to $6,000 \mathrm{kPa}$.

${ }^{c}$ The equation was derived for a limited range of suction values. 
Table 2. Data used in the development of the equations proposed in ASTM D5298-10 [Fawcett and Collis-George (1967), as cited by Greacen et al. (1987)].

\begin{tabular}{cccccccccc}
\hline $\ln \mathrm{S}(\mathrm{kPa})$ & -0.02 & 2.28 & 3.89 & 4.59 & 6.66 & 7.29 & 7.99 & 10.27 & 11.40 \\
\hline$\left(\mathrm{w}_{\mathrm{fp}}\right), \mathrm{g} / \mathrm{g}^{a}$ & 1.80 & 1.06 & 0.539 & 0.434 & 0.315 & 0.282 & 0.215 & 0.103 & 0.067 \\
\hline $\log _{10} \mathrm{~S}(\mathrm{kPa})^{b}$ & -0.01 & 0.99 & 1.69 & 1.99 & 2.89 & 3.17 & 3.47 & 4.46 & 4.95
\end{tabular}

Note: The data provided in Greacen et al. (1987)

${ }^{a}$ Each value is equal to the mean of 6 batches with 6 filter papers per batch per suction measurement.

${ }^{b}$ The values were converted directly from the $\ln (\mathrm{S})$ values provided by Greacen et al. (1987). 
Table 3. Test data originally presented in Fawcett and Collis-George (1967) ${ }^{a b}$.

\begin{tabular}{|c|c|c|c|c|c|c|c|c|c|c|}
\hline \multicolumn{2}{|c|}{$\log _{10} \mathrm{~S}(\mathrm{kPa})$} & 0 & 1.00 & 1.70 & 2.00 & 2.90 & 3.18 & 3.48 & 4.47 & 4.96 \\
\hline \multirow{2}{*}{$24361^{c}$} & $\mathrm{a}$ & 188.3 & 105.8 & 55.2 & 43.1 & 31.4 & 28.3 & 22.2 & 10.3 & 6.5 \\
\hline & $\mathrm{b}$ & 185.8 & 107.8 & 52.2 & 43.9 & 31.6 & 28.6 & 21.9 & 10.4 & 7.0 \\
\hline 24143 & & 176.6 & 106.2 & 54.5 & 42.6 & 30.3 & 27.8 & 21.6 & 10.3 & 6.7 \\
\hline 24079 & & 175.5 & 103.8 & 52.5 & 43.9 & 31.5 & 28.1 & 21.5 & 10.3 & 6.5 \\
\hline 5033 & & 171.2 & 110.2 & 52.3 & 44.2 & 31.9 & 28.4 & 21.0 & 10.4 & 6.6 \\
\hline \multirow{2}{*}{$6507^{c}$} & $\mathrm{a}$ & 195.6 & 112.2 & 53.9 & 43.0 & 31.7 & 27.7 & 21.2 & 10.4 & 6.8 \\
\hline & $\mathrm{b}$ & 189.3 & 97.8 & 59.1 & 43.3 & 31.6 & 28.3 & 21.3 & 10.4 & 6.8 \\
\hline 80435 & & 159.1 & 100.7 & 51.7 & 43.1 & 31.8 & 28.4 & 21.5 & 10.2 & 6.5 \\
\hline Mean of bat & & 180.175 & 105.563 & 53.925 & 43.388 & 31.475 & 28.200 & 21.525 & 10.338 & 6.675 \\
\hline
\end{tabular}

Note: The test results in Fawcett and Collis-George (1967)

${ }^{a}$ Test results were obtained by several research organizations using Whatman No. 42 filter paper from six different batches.

${ }^{b}$ Each filter paper water content $\left(\mathrm{wc}_{\mathrm{fp}}\right.$ ) shown in the table is equal to the mean value of the water contents of six filter papers obtained following the wetting testing procedure.

${ }^{c}$ Two sets of test results were obtained from the same filter paper batch. 
Table 4. Comparisons of suction values calculated using different calibration equations.

\begin{tabular}{|c|c|c|c|}
\hline $\begin{array}{c}\text { Filter paper } \\
\text { water content } \\
(\%)\end{array}$ & $\begin{array}{l}\text { Suction }(\mathrm{kPa}) \text { based on } \\
\text { ASTM D5298-10 }\end{array}$ & $\begin{array}{c}\text { Suction }(\mathrm{kPa}) \text { based on } \\
\text { Figure } 5\end{array}$ & $\begin{array}{c}\text { Suction }(\mathrm{kPa}) \text { based on } \\
\text { Figure } 6\end{array}$ \\
\hline 6.5 & $66,168.3$ & $67,608.3$ & $67,553.8$ \\
\hline 20.0 & $5,874.9$ & $5,984.1$ & $5,997.9$ \\
\hline 27.5 & $1,530.2$ & $1,556.0$ & $1,562.2$ \\
\hline 30.0 & 977.2 & 993.1 & 997.7 \\
\hline 35.0 & 398.6 & 404.6 & 406.9 \\
\hline 40.0 & 162.6 & 164.8 & 166.0 \\
\hline 45.0 & 66.3 & 67.1 & 67.7 \\
\hline 55.0 & 46.7 & 47.9 & 46.6 \\
\hline 70.0 & 29.3 & 30.1 & 29.5 \\
\hline 90.0 & 15.7 & 16.1 & 16.1 \\
\hline 120.0 & 6.2 & 6.4 & 6.5 \\
\hline 150.0 & 2.4 & 2.5 & 2.6 \\
\hline
\end{tabular}

Note: The suction values for filter paper water contents ranging from $6.5 \%$ to $150 \%$ calculated using the ASTM D5298-10 equations and the revised calibration equations 